\title{
Aspectos de trajetórias de professoras rurais no Paraná (1957-1979)
}

\author{
Aspects of trajectories of rural teachers in Paraná (1957-1979)
}

Aspectos de trayectorias de profesoras rurales en Paraná (1957-1979)

\section{ROSA LYDIA TEIXEIRA CORRÊA ${ }^{1}$}

\section{Resumo}

A proposta deste artigo é analisar aspectos da trajetória de professoras que atuaram em escolas primárias na zona rural, no município de Bocaiúva do Sul, no Estado do Paraná, entre os anos de 1957 e 1979. Os dados a serem trazidos neste trabalho resultam de levantamento feito junto ao Departamento de Educação da prefeitura desse município, como também de depoimentos orais obtidos por meio de entrevistas, além de documentos, como legislação, histórico escolar e portaria de admissão ao serviço público. Os resultados mostram a incipiente formação inicial dessas professoras e a gradativa formação profissional em curso normal regional. Também revelam aspectos concernentes às práticas pedagógicas desenvolvidas pelas mestras em salas de aula com turmas multisseriadas e às condições de trabalho dessas professoras, que exerciam múltiplas funções, além de garantir, em certos casos, material de escrita para o alunado.

Palavras-chave: Professoras primárias. Zona rural. Paraná.

\footnotetext{
${ }^{1}$ Doutora em História Econômica pela Faculdade de Filosofia, Ciências e Letras da Universidade de São Paulo, com estágio de pós-doutorado realizado na Universidade de Salamanca (Espanha). Professora Titular do Programa de Pós-Graduação em Educação, Mestrado e Doutorado da Pontifica Universidade Católica do Paraná. E-mail: rosa_lydia@uol.com.br
} 


\begin{abstract}
The purpose of this article is to analyze aspects of the trajectory of teachers who worked in elementary schools in rural areas, in the municipality of Bocaiúva do Sul, in the State of Paraná, between the years 1957 and 1979. The data to be brought in this work result from a survey done together with the Department of Education of the city hall of this municipality, as well as oral testimonies obtained through interviews, as well as documents such as legislation, school transcript and public service admission decree. The results show the incipient initial formation of these teachers and the gradual professional formation in teacher-training regional course. They also reveal aspects concerning the pedagogical practices developed by the teachers in classrooms with multi-series classes and the working conditions of these teachers, who had multiple functions, besides guaranteeing, in certain cases, writing material for the student.
\end{abstract}

Keywords: Elementary teachers. Countryside. Paraná.

\title{
Resumen
}

La propuesta de este artículo es analizar aspectos de la trayectoria de profesoras que actuaron en escuelas primarias en la zona rural, en el municipio de Bocaiúva del Sur, en el Estado de Paraná, entre los años 1957 y 1979. Los datos a ser traídos en este trabajo resultan de levantamiento que se realiza junto al Departamento de Educación del ayuntamiento de ese municipio, así como de testimonios orales obtenidos por medio de entrevistas, además de documentos, como legislación, histórico escolar y orden de admisión al servicio público. Los resultados muestran la incipiente formación inicial de estas profesoras y la gradual formación profesional en curso regional de profesores. También revelan aspectos concernientes a las prácticas pedagógicas desarrolladas por las maestras en aulas con grupos multiseriales ya las condiciones de trabajo de esas profesoras, que ejercían múltiples funciones, además de garantizar, en ciertos casos, material de escritura para el alumnado.

Palabras clave: Profesores primarios. Zona rural. En el estado de Paraná. 


\section{Introdução}

O objeto deste estudo é a formação de professores para atuação em escolas primárias na zona rural do Estado do Paraná ${ }^{2}$, entre os anos de 1950 e 1979. Portanto, formação e atuação inseridas em momentos conjunturais distintos da história nacional e local, marcados por transformações profundas no cenário nacional, quer do ponto de vista político, social e econômico, quer do ponto de vista ideológico.

Se os anos de 1950, são, de modo mais abrangente - em nível nacional caracterizados, sobretudo, pelo deslocamento da população rural do campo para as cidades, derivando o fortalecimento do processo industrial, em especial nos centros urbanos, onde esse potencial instaurou-se de modo ostensivo, principalmente em capitais, como São Paulo, Rio de Janeiro, Belo Horizonte, Por Alegre, o mesmo não ocorreu com Curitiba, que recebeu a população vinda do campo, bem mais tarde do que as capitais referidas. O depoimento de Schelbauer (2014, p. 78) contribui para ilustrar esse ponto de vista:

Com uma população de 1.235 .849 habitantes na década de 1940 , apenas $24,5 \%$ dos paranaenses residiam na zona urbana. As taxas de urbanização da década de 1950 apontam para índices inferiores da média nacional. Enquanto no Brasil a taxa de urbanização era de $36,1 \%$, no Paraná a mesma taxa era de $25 \%$. As maiores modificações ocorreriam no decorrer das décadas de sessenta e setenta do século 20, com o processo de urbanização e o êxodo do trabalhador rural do campo (SCHELBAUER, 2014, p. 78).

Os anos de 1950, como já registrado na historiografia (BASTOS, FONSECA, 2012; OLIVEIRA, 1997) foram marcados não somente pela reinserção e retirada de Vargas do cenário nacional mas também pela redefinição de perspectivas econômicas para o Brasil, com sua aderência a formas de relações capitalistas internacionalizantes que iriam indicar, certamente, novos rumos para o então sentido nacional desde a Era Vargas.

Tal redefinição tomaria corpo por meio do golpe civil militar, deflagrado em 31 de março de 1964. A ascensão de militares ao poder político não somente contém, de um lado, uma série de medidas coercitivas (perseguições e prisões de opositores ao regime, atos institucionais, entre eles o AI-5) mas também, por outro lado, o fortalecimento de relações de Estado com o capital internacional, com o propósito de aprofundamento de conexões de mercado com o fito da inserção do Brasil naquilo que então se considerava uma nova ordem mundial, por meio do atrelamento da indústria nacional aos imperativos de outros ordenamentos internacionais desde países de centro.

É pertinente frisar que, por certo, um aspecto central que se fará comum, tanto nos anos de 1950 quanto durante todo o período ditatorial, será a ideia da prática de planejamento com vistas, entre outras, à pretensão de solucionar problemas sociais por meio de políticas sociais, como, por exemplo, o plano de metas do período JK, cujo objetivo foi o de recuperar

\footnotetext{
2 No Paraná, segundo Schelbauer (2014, p. 80), “[...] a denominação Escola Primária Rural foi apresentada, pela primeira vez, em mensagem referente ao exercício nos anos de 1924 a 1928 e apresentada, pelo presidente de Estado, Caetano Munhoz da Rocha, ao Congresso Legislativo, indicando as 120 escolas primárias rurais subvencionadas pela União14, em conformidade com o decreto n. 13.014, de 13 de maio de 1918" (PARANÁ, 1928).
} 
o atraso econômico do Brasil, cinquenta anos em cinco, e, posteriormente, a execução de ações de governos ditatoriais visando à modernização do país.

No Paraná, as políticas sociais, entre elas a educação, assim denominadas nas duas gestões de Lupion (CORRÊA; MESQUITA; NASCIMENTO; SILVA, 2015), são destacadas como necessárias para dar respostas às demandas sociais no bojo das quais a escola primária sofreria significativa expansão em continuidade a era do interventor Manoel Ribas, nos anos de 1930 e meados dos anos 403. Demandas e necessidades sociais estão articuladas, sobretudo, a um projeto modernizador para o Estado, preocupação dos governantes, destacadamente no período que se estende entre 1930 e 1960 (SCHELBAUER, 2014).

A motivação deste trabalho decorre de pesquisa realizada junto a professoras primárias $^{4}$ que atuaram na zona rural do Estado do Paraná entre os anos de 1957 e $1970^{5}$. Dessas professoras, num total de sete, foram coletados dados por meio de entrevista estruturada (RICHARDISON, 2015; YIN, 2016). Os dados obtidos derivam-se da memória de mulheres professoras que, na ocasião da entrevista, se apresentavam numa faixa etária entre 79 e 82 anos, o que remete à acepção de Halbwachs (2013), sobre o fato de que as lembranças resultam de atividades de reconstrução do vivido num tempo e num espaço. Trata-se de um tempo de múltiplas experiências docentes, bem como de seus significados e sentidos, em um lugar que é o da escola e das relações que esta engendra. Tempo e espaço importantes também para considerar a distância de tempos e espaços vividos em relação àquilo que a memória foi capaz de recordar, considerando imperativos postos pela idade, o que implica ter em conta uma espécie de seleção operada pela memória, mas, ainda assim, não perder de vista as dimensões subjetivas que podem ser representadas pelas escolhas, pela seleção do que dizer ou não dizer (CRUIKSHANK, 2006), bem como as mitificações, criações superficiais, ou mesmo exageradas, sobre posições acerca de experiências vividas; neste caso, como professoras.

Com efeito, lidamos, sobretudo, com a perspectiva da memória de velhos (BOSI, 1994). Para essa autora, rememorar, lembrar não significa reviver, porém refazer, reconstruir as experiências do passado. Além disso, importa dizer que as lembranças de pessoas idosas contêm muito de uma história social, de elementos de vivências e experiências particulares de quem trilhou uma longa jornada. Isso atribui caráter não somente particular à memória, evidentemente, mas, sobretudo, ao significado, pelo fato de cada uma delas ter experimentado, de modo diferente, resultados de ações, que, embora tenham muito em comum, muito têm também de singular.

Assim, sem descurar dos limites e alcances que podem conter os dados orais, eles são tomados aqui como centrais à apreciação a ser feita sobre os aspectos das trajetórias

\footnotetext{
${ }^{3}$ Os anos de 1930 podem ser caracterizados pela emergência de programas destinados à escolarização das populações do meio rural no âmbito do chamado ruralismo pedagógico, voltado justamente para tais populações, cujo propósito seria fixá-las no meio rural (LIRA; MELO, 2010). Na gestão de Manoel Ribas, no Paraná, entre os anos de 1930 e 1940, foram construídas, e entraram em funcionamento, um total de onze escolas de trabalhadores rurais e de pescadores.

${ }^{4}$ A presente pesquisa teve como participantes sete mulheres, que foram professoras entre os anos 1940 e 1970. Dispuseram-se a assinar o Termo de Consentimento Livre e Esclarecido (TCLE). O Projeto de pesquisa obteve aprovação do Comitê de Ética em pesquisa, sob o protocolo n ${ }^{\circ}$ CAAE:54442416.1.0000.0020.

${ }^{5}$ Dados obtidos no curso do desenvolvimento do Projeto de pesquisa, intitulado Formação e Trabalho de Professoras e Professores Rurais no Brasil: PR, SP, MG, RJ, MS, MT, PE, PI, SE, PB, RO (décadas de 40 a 70 do século XX), sob a coordenação nacional de Rosa Fátima de Souza, em parceria internacional com o México e a Colômbia. Financiado pelo CNPQ.
} 
anteriormente anunciadas. Tais dados são cotejados em articulação com aportes da historiografia da educação, a legislação educacional do período, assim como com documentos que foram obtidos junto a uma das entrevistadas. Contudo, em se tratando de vozes de professoras com mais de oitenta anos, lidamos, ao mesmo tempo, com as ambivalências daquilo que a memória pode ser capaz de recordar, e ainda com a experiência de quem muito viveu nas lides cotidianas de ensinar a ler, escrever, contar, além de outras práticas necessárias à condição de apreensão de saberes como esses, fundamentais à sobrevivência digna de crianças, e depois adultos na vida moderna.

Posto isso, duas questões orientam a construção deste trabalho: que aspectos podem aqui ser tomados como relevantes na trajetória profissional docente dessas mulheres professoras? Que desafios se lhes foram impostos nessa trajetória? Visando responder a tais perguntas, o texto subdivide-se em três subitens, por meio dos quais buscamos atingir o propósito do estudo, que é analisar trajetórias de professoras que atuaram em escolas primárias na zona rural no município de Bocaiúva do Sul, no Estado do Paraná.

\section{A influência paterna na profissionalização: aspectos de percursos no início da docência}

A inserção de professoras primárias rurais na carreira do magistério nem sempre seguiu os contornos de exigências legais como requer o oficio. Para as sete professoras entrevistadas, não foi diferente. Tornarem-se professoras não se constituiu em uma opção $a$ priori. Foi uma atribuição paterna, como testemunha Benedita:

Fui estudar em Bocaiúva para tirar o diploma de quarta série; aí comecei a trabalhar. Aí o meu pai achou que os filhos do pessoal que trabalhava com ele - eram nove crianças que arrodeavam nossa casa -, aí ele achou que eu tinha que ensinar aquelas crianças a ler, não podia se criar, tinha até de dezesseis anos analfabeto (BENEDITA, 2016).

Ela se refere à quarta série primária. Escolarização que parecia bastar para ensinar outros que nada sabiam.

Tudo indica que Benedita iniciou suas funções na escola Itapuá, em março do ano de 1954, no município de Bocaiúva do Sul, sob a gestão do então Prefeito Pedro Antoniacomi, e do Secretário Elfredo Puppi, tendo sido exonerada, a pedido, em setembro de 1979, por meio de certidão expedida pelo prefeito municipal, Acrides Lazarotto Santos e o seu Secretário Luiz Carlos Bassetti. A documentação permite inferir que ela exerceu a função docente, concomitantemente, nas redes municipal e estadual de ensino, nessa mesma escola, a partir de 1957, sob a Portaria $n^{\circ} 1.161$, de 3 de abril de 1957, com salário de R \$ 3.000,00 (três mil cruzeiros) ${ }^{6}$. O início na profissão foi um desígnio do pai, também para Elza, conforme seu depoimento:

\footnotetext{
${ }^{6}$ A portaria do Governo do Estado do Paraná está assinada pelo então Secretário de Educação e Cultura, Vidal Vanhoni. Tal portaria garantir-lhe-ia atuar como professora efetiva, conforme apostilamento que consta no verso da referida portaria.
} 
$\mathrm{Eu}$, pra começar, meu pai achou que eu teria que estudar mais porque eu tinha só um pouco de série, até o terceiro ano. Eu fui parar na casa dos tios meus, longe, mais de trinta quilômetros, fui morar na casa deles e fui fazer a quinta série na casa do tio Chiquinho Ribeiro. Fiquei lá bastante tempo pra fazer, que agora no momento eu nem lembro, era no Salto de Santa Rita, que até hoje tem a casa lá. Daí pra gente fazer a prova, a gente vinha longe, mais de seis quilômetros pra tomar o ônibus pra ir assistir aula lá no Colégio Progresso em Curitiba; assistia aula lá e voltava pra casa da minha tia de tarde de volta [...] fiz a quinta série e depois disso daí vim pra casa. Meu pai achou que agora eu já estava pronta já, já podia trabalhar, né? E aí fiquei na casa do meu avô em Bocaiúva, um pouco de tempo também pra se preparar de volta pra começar a trabalhar. Aí também logo já fui nomeada, meu pai foi arrumando e meu avô [...] (ELZA, 2016).

Desses dois depoimentos, depreende-se que ser professora não se constituiu em algo idealizado. Certamente as circunstâncias assim definiram. De outro modo, a jovem ${ }^{7}$, residente na zona rural, pouco, ou quase nada, teria de opção profissional naqueles tempos. Observa-se que as duas professoras iniciaram o exercício docente com apenas quatro anos de escolarização.

O ingresso no magistério rural foi na condição de professoras leigas: "Nós éramos chamadas de professoras leigas; dávamos aulas, mas não tínhamos curso, não tinha diploma" (TERESINHA, 2016). A condição de professora leiga, no ingresso da carreira docente no meio rural, também é encontrada nos estudos de Lima, 2012; Marques, Santos, Pereira, Silva, 2016; Hervatini, Schelbauer, 2012; Souza, 2012. Importa dizer que, no ano de 1954, Pilotto, em relatório, enviado para o INEP, sobre a educação no Paraná, assim se posiciona:

E via-se o «déficit» no alarmante fato de todo o ensino da zona rural estar entregue a professoras comumente de formação deficientíssima, nos melhores casos de formação apenas de curso primário. Daí a política de levar a escola normal para o interior, recrutar, em cada município, os seus alunos aí mesmo, entre moças do lugar, e que aí ficassem, depois, exercendo o magistério. Foram, dentro desse espírito, criados 24 cursos normais regionais. Havia uma dificuldade, a de obter bons mestres para tais cursos normais regionais (PILOTTO, 1954, p. 97).

A formação profissional das professoras entrevistadas foi um processo ocorrido depois da inserção no magistério, em anos iniciais da escola primária. A maioria delas diz ter feito o curso normal regional, depois de começado a ministrar aulas. O curso normal regional foi instituído no âmbito das Leis Orgânicas do Ensino Normal, em 1946, por meio do Decreto-Lei n. 8.530 - de 2 de Janeiro desse ano. Nesse decreto, o curso normal regional é um dos três tipos de modalidades do ensino normal, juntamente com a escola normal e o instituto de educação (BRASIL, 1946). A modalidade denominada de normal regional destinava-se,

\footnotetext{
${ }^{7}$ As entrevistadas afirmam ter iniciado no magistério com idade entre dezesseis e dezenove anos..
} 
segundo, o decreto, a formar para o primeiro ciclo do ensino normal, ou seja, o curso de regentes de ensino primário ${ }^{8}$.

No Paraná, os cursos normais regionais tiveram impulso a partir do ano de 1848, como a criação da primeira unidade no município de Laranjeiras do Sul. Em 1958, o Estado contava com 81 unidades $^{9}$. Miguel (2011, p. 22) esclarece que

[...] os Cursos Normais Regionais que objetivavam, sobretudo, a formação no local de trabalho, de professores já em serviço cuja profissionalização formal era incompleta, tinham ainda como finalidade, o atendimento às necessidades dos alunos nos seus lugares de origem. Estas necessidades eram entendidas pelo governo, como as vinculadas à produção, ou mais especificamente às atividades de agricultura e pecuária. As propostas educacionais então implantadas assumiam tais finalidades como objetivos educacionais (MIGUEL, 2011, p. 22).

De fato, os depoimentos docentes reiteram o disposto na legislação:

[...] fiz o curso normal regional, um curso de quatro anos equivalia ao ginásio. Mas além do ginásio equivalia à escola normal porque tinha didática prática e psicologia e didática prática. Foi um curso muito difícil, um curso de quatro anos, e não foi assim tão fácil que nos deu o diploma de professora regionalista da época. Daí depois desse curso, eu fui fazer o magistério de mais três anos (TERESINHA, 2016).

\footnotetext{
${ }^{8}$ Segundo o artigo $7^{\text {a }}$ dessas leis, as disciplinas que compunham a formação para professores normalistas regionais são as seguintes: Primeira série: 1) Português. 2) Matemática. 3) Geografia geral. 4) Ciências naturais. 5) Desenho e caligrafia. 6) Canto orfeônico. 7) Trabalhos manuais e economia doméstica. 8) Educação física; Segunda série: 1) Português. 2) Matemática. 3) Geografia do Brasil. 4) Ciências naturais. 5) Desenho e caligrafia. 6) Canto orfeônico. 7) Trabalhos manuais e atividades econômicas da região. 8) Educação física; Terceira série: 1) Português. 2) Matemática. 3) História geral. 4) Noções de anatomia e fisiologia humanas. 5) Desenho. 6) Canto orfeônico. 7) Trabalhos manuais e atividades econômicas da região. 8) Educação física, recreação e jogos; Quarta série: 1) Português. 2) História do Brasil. 3) Noções de Higiene. 4) Psicologia e pedagogia. 5. Didática e prática de ensino. 6) Desenho. 7) Canto orfeônico. 8) Educação física, recreação e jogos; $\S 1^{\circ} \mathrm{O}$ ensino de trabalhos manuais e das atividades econômicas da região obedecerá a programas específicos, que conduzam os alunos ao conhecimento das técnicas regionais de produção e ao da organização do trabalho na região; $\S 2^{\circ} \mathrm{O}$ curso normal regional, que funcionar em zonas de colonização, dará ainda, nas duas últimas séries, noções do idioma de origem dos colonos e explicações sobre o seu modo de vida, costumes e tradições (BRASIL, Leis Orgânicas ....Titulo II, Capitulo, I, Art. $7^{\circ}$, grifos nossos)

${ }^{9}$ Somem-se à unidade de laranjeiras do Sul, as dos seguintes municípios: no ano de 1949: Londrina, Mandaguari, Palmas, Piraí do Sul, Pitanga, Ribeirão Claro, Rio Negro, Rolândia, Apucarana, Assaí, Foz do Iguaçu, Jaguariaíva, Sertanópolis, Siqueira Campos, Bandeirantes, Cerro Azul, Rebouças, Andirá, Tibaji; no ano de 1950: Prudentópolis, Cornélio Procópio, Wenceslau Braz, Antonina, Arapongas, Campo Mourão, Quatiguá, Tomazina; em 1953: Jandaia do Sul e Clevelândia; em 1954: Marialva e Uraí; no ano de 1956: Abatiá, Alto Paraná, Agudos do Sul, Alvorada do Sul, Cascavel, Cruzeiro do Sul, Cruzeiro do Oeste, Rondon, Guratuba, Primeiro de Maio, Ibaiti, Iguaraçu, Jandaia do Sul, Jurema, Loandra, Mandirituba, Mallet, Mandaguaçu, Maringá, Monte Castelo, Pinhalão, Paraíso do Norte, Peabiru, Rio Branco do Sul, Pinhal, São Jorge, São João do Caiuá, Santo Inácio, Santa Izabel, Ivaí, Santa Mariana, Terra Boa, Toledo; no ano de 1957: Bituruna, Bela Vista do Paraíso, Cianorte, Colorado, Congonhas, Guaíra, Jaguapitã, Leópolis, Nova Londrina, Nova Esperança, Paulo Frontin, Paramacity, Porto Vitória, Rondon, São João do Triunfo. (Paraná, Mensagem enviada a Assembleia Legislativa do Estado por ocasião da abertura da Sessão Legislativa Ordinária de 1958, pelo Senhor Moysés Lupion, Governador do Paraná. Curitiba, (PR, 1958, p. 158).
} 
Assim, a formação profissional de Teresinha também se deu depois de iniciar o trabalho docente em curso normal regional, e muito tempo depois em curso de magistério, já após a Lei $\mathrm{n}^{\circ}$ 5.692, de 11 de agosto de 1971, no bojo do período ditatorial: “[...] aí eu fui fazer o magistério, me inscrevi pra fazer o magistério, daí foi onde eu fui morar em Curitiba pra poder fazer o magistério. Nós fizemos lá na Escola Americana”, completa Diva Maria (2016).

Teresinha também iniciou sua vida como professora na condição de leiga. Segundo ela, a partir de um curso de classificação, destinado a selecionar professoras que iriam ministrar aulas, mas não tinham diploma. Nessa condição, permaneciam por muito tempo. É o caso de Benedita que cursou o quarto ano primário, mas veio a concluir o primeiro ciclo do ensino médio, no ano de 1975, de acordo com Histórico escolar emitido pelo Ginásio Estadual Campos Sales, da cidade de Campina Grande do Sul, que contém o seguinte termo:

Tendo em vista os resultados das provas prestadas no ano letivo de 1975 na $4^{\mathrm{a}}$ série do curso ginasial, orientação escolar deste estabelecimento, foi considerado habilitado no $1^{\circ}$ Ciclo do Ensino Médio, nos termos da Lei de Diretrizes e Bases da Educação Nacional (Lei no 4.024, de 20/12/1961) e respectivas normas legais complementares da Legislação estadual (PARANÁ, 1975).

Chama a atenção o ano do registro, 1975, quando estava em vigor a Lei $\mathrm{n}^{\circ} 5.692$, de 11 de agosto de 1971, o que aponta para a tardia aplicação da então nova lei educacional. Benedita obteve diploma de professora na Habilitação Magistério, em nível de $2^{\circ}$ Grau, somente no ano de 1983, pelo Instituto de Educação do Paraná.

Da escola, "um puxadinho", extensão da casa, à escola como locus de inserção pública no magistério: dimensões e relações entre público e privado “[...] Então, meu pai fez um puxadinho lá no moedor de erva (ele lidava com erva) e daí a prefeitura deu, não sei se dez carteiras, foi aí que eu comecei” (BENEDITA, 2016).

A relação entre público e privado indicada nesse discurso está próxima das relações cotidianas quando o trabalhador constrói um puxadinho em sua casa para ali funcionar uma escola, e o prefeito doa dez carteiras. Não é muito diferente do que ocorre com os professores que chegam a completar seu período de estudos: “[...] quando eu me formei, o marido da professora foi e falou pro prefeito da época, não sei se era o Ari Bandeira. Ele disse que arrumasse uma classe pra mim que eu tinha condições" (BELEZARIA, 2016). "Eu comecei aqui, inclusive fundei a cadeira da terra boa, que não tinha, nunca tinha tido aula antes; fundei a cadeira e comecei como professora municipal e leiga" (TEREZINHA, 2016). Esses depoimentos demonstram que, mesmo tendo o Paraná expandido consideravelmente a rede de escolas rurais, havia localidades que ainda prescindiam desse tipo de escolas. As sete entrevistadas iniciaram a trajetória profissional nos fins dos anos de 1950. Ainda que muitas iniciativas governamentais tenham sido levadas a cabo, do ponto de vista da formação e da melhoria do trabalho pedagógico ${ }^{10}$, muito ainda precisaria ser feito no sentido de melhorar a formação e a inserção da professora primária rural naquele Estado.

A propósito da relação público privado, ela tem início no período colonial, tomando, posteriormente, diferentes contornos. Para Severino (2005), as categorias de público e

\footnotetext{
${ }^{10}$ Ver, nesse sentido, o trabalho referido de Miguel (2011).
} 
privado, no contexto da educação brasileira, podem ser entendidas em três momentos histórico-sociais. O primeiro abrange o período colonial até a revolução de 1930. Nesse período, a ideia de público parece esvaziada; a supremacia privada é representada pela igreja católica. Com o advento da República, não houve ruptura com o formato relacional anteriormente posto. O segundo momento é demarcado entre 1930 e 1964, com o avanço do capitalismo industrial e a crescente urbanização. "Neste contexto, a dimensão pública afirmase como uma alternativa autônoma e positiva para a condução das políticas sociais, em geral, e da política educacional, em particular" (SEVERINO, 2005, p. 32) ${ }^{11}$.

Nota-se que embora, no dizer de Severino, o Estado firme-se em sua dimensão pública no período de 1930 a 1964, certamente resquícios daquelas relações presentes no período colonial ainda persistem. Tudo indica que, nesse período, principalmente no pósSegunda Guerra, apesar de a faceta do Estado do Bem Estar Social comece a alinhavar-se, ela não é suficiente para estender-se em muitos de seus desdobramentos; neste caso, aos municípios, onde muitas vezes faltam não somente a vontade política mas também recursos financeiros para investimentos educacionais, quer em termos de formação de professores, quer no que diz respeito à construção de escolas primárias.

Vale ainda destacar que, no espaço contraditório das relações Estado e sociedade, o Estado do Paraná, no período de 1930 a 1960, construiu um número importante de escolas primárias em distintas modalidades, quais sejam:

[...] as escolas de trabalhadores rurais e de pescadores, subordinadas ao Departamento de Agricultura, da Secretaria de Obras Públicas, Viação e Agricultura - Seção de Ensino Profissional e, posteriormente, ao Departamento de Ensino Superior, Técnico e Profissional, vinculado à Secretaria de Agricultura do Estado; o grupo escolar rural e a escola primária rural, modelo de escola isolada que atendia às populações rurais, também denominadas nos documentos como Casa Escolar Rural. Estas últimas estiveram subordinadas à Secretaria do Interior, Justiça e Instrução Pública e, posteriormente, à Secretaria de Estado da Educação e Cultura (SCHELBAUER, 2014, p. 80).

Considerando as modalidades de escolas primárias construídas no início dos anos de 1960, o Paraná somava 6. 970 unidades, segundo dados estatísticos do Estado, do ano de 1958. Essas unidades foram construídas num intenso processo de expansão de escolas no Estado, inicialmente no Governo do interventor Manoel Ribas (1932-1945), e, posteriormente, em duas gestões não consecutivas, de Moyses Lupion (1947-1951 e 19561951). Nesse período, casas escolares foram edificadas, em função de acordo firmado entre o Estado do Paraná e o Ministério da Educação e Saúde. Ney Braga, ao assumir o governo do Estado, em 1961, questiona o fato de que haviam sido construídas escolas, que não funcionaram por falta de professores.

${ }^{11}$ Para esse autor, depois do golpe de 1964, implanta-se um novo modelo, consequente da nova organização social, em conflito com a Igreja Católica. Há consolidação do Estado brasileiro, também com a consolidação do sistema público de ensino. O embate entre católicos e liberais põe em cena um terceiro elemento demarcado pelos empresários da educação, hegemônico na relação público-privado a partir dos anos de 1970. O estado militar caracteriza a relação público-privado por meio da ideia de produtores e consumidores da educação (SEVERINO, 2005). 
As professoras informaram que ensinavam em escolas isoladas. Essa modalidade de escola foi a mais disseminada no Estado. Nos anos de 1956, somente para termos uma ideia, elas somavam, no Estado, 2.617 unidades (CORRÊA; MESQUITA; NASCIMENTO; SILVA, 2015). Apesar disso, as professoras fizeram referência ao fato de que havia carência de escolas na zona rural de pequenos municípios, bem como de professoras habilitadas para tanto.

\section{Práticas pedagógicas: desafios cotidianos da docência}

Aspectos peculiares sobre as práticas pedagógicas desenvolvidas pelas mestras em salas de aula com turmas multisseriadas, chamam a atenção nos depoimentos:

Se fosse uma escolinha simples que nem a da Dita aqui, que era só ela, ela tinha as três classes e a minha era as duas Divas aqui que estavam dando aula; então, era distribuído, ela ficava com o primeiro e segundo e eu com a terceira e a quarta (DIVA, 2016).

Era multisseriada, por exemplo: eu punha o primeiro ano numa carreira de carteira, segundo, terceiro, quarto já era mais pouco que nunca iam até a quarta, muitos alunos (BENEDITA, 2016).

As escolas com turmas muitisseriadas são comuns no interior do Brasil ainda em tempos atuais. Experiências nesse sentido também são trazidas nos estudos de Paim (2012) e Souza (2012). Eles indicam semelhantes dificuldades cotidianas do fazer pedagógico, no qual as professoras deveriam antes de tudo ser criativas na organização da dinâmica do fazer docente diário.

No bojo do exercício docente, destaca-se o que pode ser chamado de arte de ensinar, com e sem o uso do quadro negro, por exemplo, além da distância entre prescrições oficiais e reais condições de ensino.

Dividia o quadro, antigamente; bem no começo era um quadro de um, acho que até veio da madrinha aquele quadro, da escola dela. O quadro tinha um e vinte de tamanho (BENEDITA, 2016).

Eu e tinha um quadrinho só e mais nada (BELIZÁRIA, 2016).

[...] nunca dividi. Eu dava, por exemplo, a aula que fosse de leitura ou o que, enquanto ensinava a outra classe pra não misturar. Então, eles ficavam lendo enquanto dava aula pra outro, pra não dividir o quadro porque eles não prestavam atenção, passa uma coisa aqui e outra aqui pra ver, eu, por exemplo, não usei dividir (DIVA, 2016).

A minha dificuldade era quadro negro, né? Então tinha um com um metro por um e vinte. Isso eu lecionei acho que uns vinte anos, depois é que eles deram um de dois metros por um, aí melhorou (BENEDITA, 2016). 
Elas trazem os limites e as alternativas para lidar com o quadro negro, ao que tudo indica pequeno, em relação ao número de alunos em sala de aula, e à necessidade de distribuir atividades que deveriam ser destinadas aos alunos da primeira à quarta série. $\mathrm{O}$ depoimento de Benedita traduz um longo tempo de uso, vinte anos. Muito tempo para atualizar um suporte pedagógico de tamanha tradição na cultura material escolar. Tempo no qual, dizem, era difícil os alunos adquirirem livros. Muitas vezes, elas tinham de lhes oferecer os cadernos para a escrita. $\mathrm{O}$ uso do quadro, por meio de sua divisão com atividades para uns, e a concomitante leitura individual para outros de séries diferentes daquela para a qual Benedita registrava as atividades a serem feitas, demonstra um pouco daquilo que as pessoas fazem dos objetos que lhes são impostos (CERTEAU, 1994). Para elas, a formação e a condição escolar que lhes foi propiciada não foram suficientes ante as demandas sociais que eram muitas.

Tinha coisa também que eles passavam pra gente e a gente não tinha como aplicar, por causa que não tinha condições. Não tinha luz elétrica naquele tempo na nossa escola, aí meu pai fez uma usina, então tinha luz na minha casa, da minha irmã e na casa escola, mas foi a primeira que teve luz elétrica (BENEDITA, 2016).

Além de garantir, em certos casos, material de escrita para o alunado, elas também deveriam prover a escola de condições de funcionamento, angariar recursos financeiros bem como exercer múltiplas funções:

Mas nunca chegava na verdade. Às vezes saída do bolso da professora pra continuar, pelo menos pra mim não chegava. Eu cansei de comprar caderno grossinho assim pra dar uma folha pra cada aluno pra levar a liçãozinha pra casa.

E nós fazia festa lá na Barragem.

É, lá tinha gente a mais.

Lá tinha quatrocentos alunos.

E aí com o dinheiro da festa comprava algo para a escola. Comprava tudo o que faltava, até se morresse uma criança nós fazíamos o funeral. Nós tinha dinheiro em caixa.

Era tudo na responsabilidade do professor. A professora dentro da sala de aula era professora, era médica e era dentista, era zeladora e principalmente zeladora. Tinha que ter a sala de aula limpinha.

E cozinheira.

Cozinheira ainda, tinha escola que tinha horta e tinha que ir capinar a horta (BENEDITA, 2016).

O livro didático esteve presente nas práticas escolares,

Tinha o livro do professor que tinha as perguntas e respostas; depois o que a gente não sabia você olhava ali (DIVA, 2016). 
Tinha livro, como que é? De poesia, nossa, as crianças adoravam. A gente fazia trabalho de dia da bandeira, dia do soldado (ELZA, 2016).

Tinha os tinteiros nas carteiras, tinha que molhar a canetinha com a peninha pra poder escrever e tinha o mata-borrão e não podia sujar as mãos (ELZA, 2016).

O livro didático é também elemento de tradição da cultura escolar. Naquele momento, constituía-se num guia imprescindível: o que a gente não sabia, olhava ali. É histórica a importância atribuída a essa materialidade escolar. A importância atribuída a esse tipo de livro pelos organismos de ensino e sequencialmente pela escola faz com que ele seja determinante no trato dos conteúdos escolares e mesmo nas determinações pelo professor.

Outro aspecto importante a ser mencionado é a ênfase nos depoimentos sobre a relação entre alunos e professoras, caracterizada pela respeitabilidade à hierarquia, ao saber pretensamente representado por elas. As professoras relembram, com certo orgulho, os resultados do trabalho que desenvolviam com as crianças:

E daí é isso aí: gostava de dar aula e tudo. Na época, já foi falado, que os alunos respeitavam, aquela coisa, né, e as crianças aprendiam né? Olhe terceira, quarta série, as crianças saíam dali sabendo regra de três, juros, tudo essas coisas, eles sabiam tudo, tudo. No primeiro ano, a criança já sabia ler e escrever, fazer continha de multiplicar e de dividir até nove, no primeiro [...] (DIVA MARIA, 2016).

Elementos da memória, às vezes, aparecem demarcados em certos testemunhos, sobre os tempos de exercício de docente:

Foi, foi bom; nós vivia daquilo, a gente era uma autoridade perante os pais, as crianças, vivemos muito bem, era o nosso ganha pão, foi muito bom e fez aquilo que a gente gostava.

A gente fazia com amor.

E a gente aprendeu muita coisa, através disso a gente aprendeu.

Foi muito bom.

Com certeza.

É, foi.

Se nós ficasse como foi nomeada, a gente parava. Nossa o quanto que a gente aprendeu! (BELIZARIA, 2016).

Bosi (2009), referindo-se à memória de velhos, lembra-nos como referenciam esses últimos depoimentos, de que "a lembrança é sobrevivência do passado que se conserva no espírito de cada ser humano, no aflorar da consciência em forma de imagem-lembrança. Ser professora não foi somente ensinar, mas, sobretudo aprender, para ser professora e aprender com os alunos; tudo leva a crer". Aprender nas relações sociais. "Foi bom, muito bom" com certeza parece resultar de um conjunto de lembranças esboçadas, cujas imagens estão eivadas de sentimentos postos pelos significados atribuídos a cada uma das experiências vividas. 


\section{Considerações finais}

O trabalho com depoimentos orais das professoras que atuaram entre os anos de 1957 e 1979 não estava no script inicial; foi decorrência de um processo inicial de investigação em busca de fontes documentais escritas que nos fez chegar a um grupo de professoras aposentadas e ainda residentes na cidade onde sempre viveram e atuaram em classes multisseriadas de escola primária e de primeiro grau.

Desse modo, foi-nos lançado o desafio de saber um pouco da formação dessas professoras e de suas inserções nesse universo de ensinar e aprender na escola dos primeiros conhecimentos.

De uma aproximação metodológica individual, em que os documentos foram motivo para o rememorar com D. Benedita, ampliamos o procedimento para um encontro coletivo, no qual companheiras de profissão pudessem lembrar em conjunto, ou individualmente, contando com a ajuda de outra. Muitos dos trechos dos depoimentos colhidos resultam de reafirmações, complementações de um "detalhe" para tornar o acontecimento lembrado preciso, detalhado, objetivo.

\section{Referências}

BASTOS, Pedro Paulo Zahluth; FONSECA, Pedro Cezar Dutra (Org.): A era Vargas: desenvolvimentismo, economia e sociedade. São Paulo: Editora da UNESP, 2012.

BELEZARIA. Entrevista. Campina Grande do Sul (Paraná), 16 maio 2016.

BENEDITA. Entrevista. Campina Grande do Sul (Paraná), 16 maio 2016.

BOSI, Acléa. Memória e sociedade: lembranças de velhos. São Paulo: Companhia das Letras, 1994.

BRASIL. Decreto-Lei no 8.530, de 2 de janeiro de 1946. Lei Orgânica do Ensino Normal. Diário Oficial [da] União, Poder Executivo, Brasília, DF, 4 de janeiro 1946. Seção 1, p. 116. Disponível em: http://www2.camara.leg.br/legin/fed/declei/1940-1949/decreto-lei-8530-2janeiro-1946-458443-publicacaooriginal-1-pe.html. Acesso em: 2 abr. 2017.

. Lei $\mathrm{n}^{\circ}$ 5.692, de 11 de agosto de 1971. Fixa as Diretrizes e Bases para o ensino de $1^{\circ}$ e $2^{\circ}$ graus, e dá outras providências. Diário Oficial [da] União, Poder Executivo, Brasília, DF, 12 de agosto de 1971. Seção 1, p. 6377. Disponível em: http://www2.camara.leg.br/legin/fed/lei/1970-1979/lei-5692-11-agosto-1971-357752publicacaooriginal-1-pl.html. Acesso em: 4 abr. 2017.

CERTEAU, Michel de. A invenção do cotidiano: artes de fazer. Petrópolis: Vozes, 1994

CORREA. Rosa Lydia Teixeira; MESQUITA, Ilka Miglio; NASCIMENTO, Ester Fraga Vilas-Boas Carvalho do; SILVA, Rony Rei do Nascimento. Expansão da escola, história comparada entre Sergipe e Paraná (1939-1961): entrecruzando olhares. In: SOUZA, Rosa 
Fatima de; PINHEIRO, Antonio Carlos Ferreira; LOPES, Antonio Padua de Carvalho (Org.). História da escola primaria no Brasil: investigações em perspectiva comparada em âmbito nacional. Aracaju: EDISE, 2015.

CRUIKSHANK, Julie. Tradição oral e história oral: revendo algumas questões. In: FERREIRA, Marieta de Moraes; AMADO, Janaina. Usos e abusos da história oral. Rio De Janeiro: Editora FGV, 2006.

DIVA. Entrevista. Campina Grande do Sul (Paraná), 16 maio 2016.

DIVA MARIA. Entrevista. Campina Grande do Sul (Paraná), 16 maio 2016.

ELZA. Entrevista. Campina Grande do Sul (Paraná), 16 maio 2016

HALBWACHS, Maurice. A memória coletiva. Tradução Beatriz Sidou. 2. ed. São Paulo: Editora Centauro, 2013.

HERVATINI, Luciana; SCHALBAUER, Analete Regina. A Escola Normal Regional no interior do Paraná: a realidade e a idealidade de suas práticas pedagógicas. Revista HISTEDBR, Campinas, v. 12, n. 45, p. 296-309, mar. 2012. https://doi.org/10.20396/rho.v12i45.8640150

LIMA, Sandra Cristina Fagundes de. História do ensino rural em Uberlândia-MG: memórias e práticas de professoras (1926-1979). Educação em Perspectiva, Viçosa, v. 3, n. 1, p. 127-149, jan./jun. 2012

LIRA, Débora Amélia N. de; MELO, Amilka Dayane Dias. A educação brasileira no meio rural: recortes no tempo e no espaço. In: CONFERÊNCIA NACIONAL DE POLÍTICAS PÚBLICAS CONTRA A POBREZA E A DESIGUALDADE, 1; 2010, Natal. Anais... Natal: Universidade Federal do Rio Grande do Norte, 2010.

MARQUES, Tatyanne Gomes; SANTOS, Deusliana Pereira Silva; PEREIRA, Eunice da Rocha; SILVA, Marieuda Cardoso Guimarães. Práticas docentes de professoras leigas em escolas no campo: uma análise das histórias de vida. Cadernos Cenpec, São Paulo, v. 6, n. 1, p. 96-119, jan./jun. 2016.

MIGUEL, Maria Elisabeth Blanck. As escolas rurais e a formação de professores: a experiência do Paraná 1946-1961. In: WERLE, Flávia Obino Corrêa (Org.). Educação rural em perspectiva internacional: instituições, práticas e formação de professores. Ijuí: Unijuí, 2007.

MIGUEL, Maria Elisabeth Blanck. A formação do professor para as escolas rurais no Paraná no contexto das políticas de educação nacionais e internacionais. Revista HISTEDBR, Campinas, v. 11, n. 43, p. 21-31, set. 2011. 
OLIVEIRA, Francisco de. Viagem ao olho do furacão: Celso Furtado e o desafio do pensamento autoritário brasileiro. Novos Estudos CEBRAP, São Paulo, v. 2, n. 48, p. 3-19, jul. 1997.

PAIM, Elison Antônio. Rememorando o fazer-se professor (a) em escolas multisseriadas na Região oeste de Santa Catarina. In: PAIM, Elison Antônio; REBELO, Gianik; COSTA, Marli de Oliveira (Org.). História da educação e cultura escolar. Chapeco: Argos, 2012.

PARANÁ. Secretaria de Estado da Educação e Cultura. Portaria $n^{\circ} 1$. 161, de 3 de abril de 1957. (datilografado).

. Histórico escolar de Benedita da Luz Oliveira Bandeira. Ginásio Estadual Campos Sales, 1975.

. Mensagem enviada à Assembleia Legislativa do Estado por ocasião da abertura da Sessão Legislativa Ordinária de 1958, pelo Senhor Moysés Lupion, Governador do Paraná. Curitiba, 1958.

PILOTTO, Erasmo. A educação no Paraná: síntese sobre o ensino público elementar e médio. Rio de Janeiro: Ministério da Educação e Cultura/Instituto Nacional de Estudos Pedagógicos, 1954.

RICHARDSON, Roberto Jarry. Pesquisa social: métodos e técnicas. São Paulo: Editora Atlas, 2015.

SCHALBAUER, Analete Regina. Da roça para a escola: institucionalização e expansão das escolas primárias rurais no Paraná (1930-1960). História da Educação, Porto Alegre, v. 18, n. 43, p. 71-91, maio/ago. 2014.

SEVERINO, Antônio Joaquim. O público e o privado como categoria de análise em educação. In: LOMBARDI, José Claudinei; JACOMELI, Mara Regina Martins; SILVA, Tânia Mara da (Org.). O público e o privado na história da educação brasileira: concepções e práticas educativas. Campinas: Autores Associados, 2005.

SOUZA, José Edimar de. Trajetória, docência e memórias de uma professora: fragmentos do ensino rural em Novo Amburgo/RS 1940-1969. Revista Historia de la Educação Laatinoamericana, v. 14, n. 18, p. 265-280, jan./jun. 2012.

TERESINHA. Entrevista. Campina Grande do Sul (Paraná), 16 maio 2016.

YIN, Roberto K. Pesquisa qualitativa do início ao fim. Porto Alegre: Editora Penso, 2016. 